\title{
Integrated reproductive health services: the perspectives of providers
}

\author{
Pranitha Maharaj, School of Development Studies, University of KwaZulu-Natal
}

\section{Abstract}

With the advent of the AIDS epidemic the focus of family planning programmes has shifted from an emphasis on pregnancy prevention to include disease prevention. The move towards integration has meant a major re-orientation in the role of health providers. This article seeks to expand knowledge about the implementation of integrated services from the perspective of providers. It focuses more specifically on the provider's perceptions and experiences of integrated services. A range of methods is used to obtain information from providers, including an inventory of health facilities, in-depth interviews and focus group discussions. The results suggest that the majority of providers expressed favourable attitudes to integrated services. Integrated services are seen as a more client centred approach. However, there is a lack of clarity about the precise form that integration should take. As a result, providers seem more comfortable with the traditional focus on family planning and maternal and child health than sexually transmitted infections.

\section{Introduction}

At the International Conference on Population and Development (ICPD) in Cairo held in 1994 delegates from more than 180 countries committed themselves to transforming and expanding existing family planning programmes to encompass a more comprehensive, client centred approach to reproductive health. The conference shifted the emphasis away from a narrow focus on demographic targets towards meeting the reproductive goals of individual men and women. Over the past few decades, family planning programmes have made outstanding progress in expanding contraceptive use and reducing fertility rates (Bongaarts and Johannson, 2002:24). However, this is occurring in the context of a high prevalence of HIV/AIDS. At the end of December 2002, there were 42 million people living with HIV/AIDS (UNAIDS, 2002:3). With the advent of the AIDS pandemic, there has been renewed interest in the prevention and control of sexually transmitted infections (STIs). STIs, which are a major public health concern in many parts of the world, were hitherto largely neglected (Mayhew, 1998:1). The link between HIV and STIs has highlighted the need for early detection and proper management of STIs. Controlling the epidemic of conventional STIs will reduce STI complications as well as the further spread of HIV/ AIDS (Grosskurth, Mosha and Todd, 1995:530).

The growing interest in, and practice of contraception and the high incidence of STIHIV infections is likely to have profound implications for individuals, for services, for programmes and for policies (Zaba, Boerma and Marchant, 1997:3). In the absence of any other primary health care (PHC) service, there has been an emphasis on integrating
HIV/STI services within mainstream maternal and child health and family planning programmes (Lush, Walt, Cleland and Mayhew, 2001:30). This shift is based on the belief that combining family planning, maternal and child health services; and STI/HIV services may be the most convenient and effective way of providing cost effective and better quality services to sexually active women. However, this will involve a major re-orientation in the role of service providers.

The aim of this research is to provide some insights into the integrated reproductive health approach from the perspective of providers. It builds on earlier research conducted in KwaZulu-Natal to determine staff ability and preparedness to prevent the spread of AIDS (Abdool Karim, Preston-Whyte and Abdool Karim, 1992:360), but looks more specifically at the response of health providers to the twin risk of unwanted pregnancy and STI/HIV infection. It draws heavily on interviews conducted with providers in order to understand their perspectives of, and experiences with, providing integrated services. The focus is more specifically on the knowledge and skills of providers and their attitudes to integration. As the primary point of contact between clients and reproductive health programmes, providers are not only an important source of information, but are ultimately the agents for improving service delivery (Helzner and Roitstein, 1995: 81).

\section{The Context}

This study was conducted in an urban and rural site in KwaZulu-Natal. Both the rural and urban sites are inhabited primarily by Zulu speaking people of low socio-eco- 
nomic status. The rural site is KwaDumisa- a sub-district of Umzinto-Vulamehlo District- situated approximately 80 kilometres south west of Durban. Varga (1999:17) described KwaDumisa as "typical of impoverished rural hinterlands throughout South Africa". The urban site is the former African township of Ntuzuma. Ntuzuma is similar to other urban African townships in South Africa. Homes, roads and schools are in need of repair and electricity and water supplies are constantly interrupted (LeClerl-Madladla, 1997:365). Unemployment in Ntuzuma is relatively high at about 20 percent (Development Bank of South Africa, 1998:159). Both areas have been selected because of the high level of HIV infection among antenatal clinic attendees.

\section{Research Design Research Approach}

This research relied on a diverse range of qualitative methods to obtain information about what services were integrated and how they were integrated and the implications of this on the delivery of services. Qualitative methods are appropriate for providing an understanding of the meaning and context of behaviours and the processes that take place within social relationships (Neuman, 1994: 30). Moreover, it provides an opportunity for exploring in more detail complex and sensitive issues that may not be possible in largescale surveys. A triangulation of methods were utilised to ensure greater validity of data and also provide a more detailed understanding of the process of integration from the perspective of providers. The use of a number of data sources allows for the exploration of the some of the main areas of interest from a variety of angles and benefits from the unique insights offered by each (Simmons and Elias, 1994:6).

\section{Methods of data collection}

In order to gain access to health facilities, permission had to be obtained from the provincial department of health to conduct the research. Ethical approval to conduct the study was first obtained from the ethics committee at the University of Natal before the department of health consented to the research. Once permission was obtained, telephonic appointments were arranged to visit the health facilities. The fieldwork for the study took place from February to April 2001. There were four field workers that were employed to assist in the research. In the first part of the study, information on accessibility, physical infrastructure, supplies, equipment, and training and the staffing situation was collected at each facility. The aim of the inventory was to assess the operational capacity of health services currently providing family planning and maternal and child health services in order to determine the feasibility of providing integrated services. In each area, four government facilities were sampled. This study was limited to government facilities because the vast majority of men and women rely on the government for meeting their health needs. The inventory was completed by observing the facilities that are available and through discussions with senior staff at the health facility. The inventory consisted of a checklist of items. The inventory was completed by observing all the facilities that were available and through interviews with senior staff at the health facility. In most facilities, it was possible to verify that the items existed by actually observing them.

In-depth interviews were held with senior staff at all government health facilities at each of the eight facilities. The aim of the in-depth interviews was to provide a detailed picture of the integration process at the district level. The in-depth interviews provided information on the progress made in implementing policies at the district level, with specific focus on changes in training, administrative and operational systems. The in-depth interviews explored in detail the experiences of staff with programme activities and provided insights into the impact of national policies from the perspective of senior staff. The in-depth interviews also provided information on the practical implications of implementing integrated services especially with regard to STI prevention and management activities. In each selected health facility, one senior staff member was interviewed. The senior member of staff was purposively selected based on their position within the organisation. In most cases, this was the person in charge of family planning or maternal and child health services. Informed consent was obtained prior to the interview. An appointment was arranged in order to avoid disrupting the normal activities at the health facility. Senior staff was assured that all their responses would be kept strictly confidentiality. All the interviews, apart from one who refused, were tape-recorded.

Focus group discussions were held with providers offering family planning or maternal and child health and STI services. The focus group discussions generated information on provider's experiences and the benefits and barriers to integration. With the advent of the HIV epidemic many family planning and maternal and child health providers have had to broaden their focus to include a wide range of reproductive health services. A total of four focus group discussions were held: two in the rural site and two in the urban site. Participants for the focus group discussions were recruited through direct contact with providers at treatment/service facilities. Providers were then asked if they would be willing to participate in the study. Each focus group contained between six to eight people. Participants were informed of the tape-recorder and the importance of recording the correct language and issues of concern to them. The moderator also assured participants of confidentiality and that anonymity will be maintained at all times. The interview guide for the focus group discussions was the same as the in-depth interviews. The results from the focus group discussions were used to complement the information obtained from the in-depth interviews.

\section{Data Analysis}

The interviews were tape-recorded and extensive field notes were compiled during fieldwork. The tapes were translated and transcribed. All the transcripts were read and reread and organised according to particular themes and assigned initial codes. Initial coding refers to "the process of breaking down, examining, comparing, conceptualising and cat- 
egorising data" (Strauss and Corbin, 1990:61). After initial coding, all the data were assembled under particular themes. In the final analysis, the codes were modified and recurrent themes that emerged across the transcripts were identified. The aim was two-fold: firstly, to identify common themes and secondly, to identify issues of controversy and debate. The computer package, Ethnograph, was used to assist with data analysis. The transcripts were used to illustrate particular findings and to provide some interpretations.

\section{Trustworthiness}

To establish trustworthiness of the study, Guba's model (Krefting, 1991) was used. This model uses four criteria for assessing the value of the findings of qualitative research: credibility, applicability, consistency, and conformability. In applying these criteria to the study the following measures were adopted. The participants were given the opportunity to read the transcripts and verify the researcher's interpretations and conclusions. Also, a detailed outline of the methodology was provided in order to enable others to determine whether the findings of the study were applicable to another context. In addition, the tape recording of the interviews provided another mechanism for the independent analysis of the data. Finally, the use of a combination of methods was useful for confirming or validating results.

\section{Results}

\section{Perceived benefits and barriers to integration}

Despite international agreement on the need for integration, there is little consensus about what is meant by integration (Dehne, Snow and O'Reilly, 2000: 629; Lush, Cleland, Walt and Mayhew, 1999:771). Lush, Cleland, Walt and Mayhew (1999:773) points out that at the service level, the definitions of integration have ranged from the supermarket approach, in which clients see a single provider for all their reproductive needs, to the teamwork approach, in which the provider refers clients to separate providers. In general, there are essentially two sets of STI activities that can be integrated into family planning: those relating to STI prevention and those relating to STI management. In addition, the promotion and distribution of condoms (or other barrier methods) may be introduced into family planning as a new activity (Finger, 1994:4).

The process of integration is progressing slowly in health facilities and is implemented in many different ways. Most health facilities are either partially or fully integrated. In some health facilities, clients see one provider for all their reproductive health needs. In other health facilities especially the larger clinics and hospitals, services are provided concurrently, rather than having separate services on separate days. This means that clients have to queue separately for separate services. All health facilities claimed to offer a complete range of services on a daily basis but this is not always the case. For example, antenatal services are usu- ally offered on specific days of the week.

In general, providers expressed favourable attitudes to integrated services. In the in-depth interviews it became clear that integrated services are seen as a more comprehensive approach to the client. Clients are offered a range of services on a single visit. Integrating services is therefore seen as a more comprehensive approach to the reproductive needs of clients. Integrated services are seen as benefiting clients because it reduces their travelling times and clients are saved the inconvenience of coming to the clinic on many separate occasions, as is illustrated in the following comment.

"Clients are offered a full range of services at the clinics. They receive all the services that they need on one day. They don't have to come to the clinic on different days" (Rural, In-depth Interview).

The provision of integrated services also reduces the waiting time of clients. Clients no longer have to join separate queues for separate services. Some providers also felt that integrated services allow the client to develop a relationship of trust with providers. Moreover, it helps to prevent duplication and ensure continuity in services.

A major concern has been the stigma traditionally associated with some services and its implications for attendance. Some providers have suggested that the provision of integrated services may reduce the stigma attached to STI services. Moreover, integrated services has the potential of reaching under-serviced segments of the population, for example, men and women coming to the health facility for STI services, as is demonstrated in the following comment:

"I don't think we should separate services because STI clients may be stigmatised. If services are separated people will say if they are going there, it means that they have a STI" (Urban, In-depth Interview).

Many providers felt that in the beginning there was a lack of clarity about what services should be integrated and how they will be implemented. The lack of clear guidelines at the policy level created difficulties at the service provision level and the implementation of integrated reproductive health services. In the absence of clear guidelines, many providers have had to rely on their own instincts for delivering integrated services. As a result, the implementation of integrated services was unstructured and unplanned. Some of the health facilities have been able to overcome some of the earlier resistance, as providers became more comfortable with providing these integrated services.

One of the rationales for the integration of STI into family planning or maternal and child health services is that providers of these services require similar skills for addressing the needs of clients (Pachauri, 1994:325). Providers were more likely to receive training in delivery of family planning or maternal and child health than STI services. In the focus groups it became clear that providers felt that they would benefit from additional training. 
"Staff need to be trained to provide integrated services. Many of the nurses are trained in specialist fields. They have to be trained to provide other services. At the moment many feel that they can't provide services to certain clients"(Urban, In-depth Interview).

Staff may experience 'role expansion', being asked to undertake tasks for which they are not prepared. This may reduce workers' morale and motivation and can ultimately lead to a decline in the overall quality of the services. Some providers also complain that it is difficult to provide personalised, specialised services to clients because of the large client load. At some health facilities the situation is so serious that clients may be turned away without receiving services.

"The protocol says that you must see 30 clients a day, but you can't see only 30 patients. You end up with 60 patients. If clients are turned away they may become violent. There is nothing we can do but provide them with a limited range of services" (Urban, Focus group discussion).

One of the justifications for the integration of services is that the basic physical environment required to provide STI services are similar to that required for family planning or maternal and child health services (Pachauri, 1994:339). However, the physical structure of the health facility may impose severe limitations on the delivery of services. Some of the health facilities have limited working space, which may result in a lack of privacy and confidentiality.

"This building was originally somebody's house. It was converted into a clinic. It is very small. We don't have enough consulting rooms. Most of the clients are not able to fit into the clinic. There are usually long queues outside the building" (Urban, In-depth Interview).

The essential equipment required for providing good quality services was not always adequate in most of the health facilities, especially in the rural area. All of them had a blood pressure machine, needles, syringes, and the speculum. However, some health facilities were missing essential equipment. For example, two out of the four health facilities visited in the rural area did not have any sterilising equipment. Furthermore, essential equipment was not functioning properly. Moreover, where the equipment was available, it was sometimes shared between various sections. The shortage of essential equipment is likely to have serious implications for delivery of services.

\section{STI Prevention Activities}

Health facilities are seen as an appropriate and acceptable setting for communicating messages about family planning and maternal and child health and STIs/HIV/AIDS (Pachauri, 1994:331). The aim of prevention activities is to inform, educate and counsel clients on STIs, health seeking behaviour and behaviour to reduce the risk of transmission (Dehne, Snow and O'Reilly, 2000:630).

Information, Education and Counselling (IEC): IEC is provided to clients mainly through educational materials, group talks and individual counselling. IEC has a key role to play in changing sexual behaviour and preventing unwanted pregnancy and STIs (including HIV/AIDS) (Pachauri, 1994:331). In many of the health facilities IEC materials are available and they cover a range of topics. However, some health facilities reported shortage of educational materials. Another problem is that these materials may not be in the local language and as a result their messages may not be effective.

Condom Promotion: Condom promotion is an important component of integrated services (Finger, 1994: 4). Integrated services provide an ideal opportunity for promoting condoms as a method of dual protection against unwanted pregnancy and diseases. In most health facilities condoms are available in boxes in the waiting room. Condoms are widely recognised as a method of preventing pregnancy and STIs/ HIV. However, condoms are more likely to be associated with STIs/HIV. As a result, providers are more likely to promote condoms to clients suffering from STIs than family planning clients.

"Women who come for STI treatment are encouraged to use condoms with their partners. However, women report that they are not able to convince their partners to use condoms. They complain that sex with a condom is not pleasurable. Men say that they can't eat a sweet wrapped in paper" (Rural, In-depth Interview).

Providers are more likely to recommend more effective, female methods for preventing pregnancy to family planning clients. As providers are aware that women may face obstacles from their male partners they recommend methods that they can use without consulting their partners. Condom use depends on the male partner's co-operation and some women may experience difficulty convincing their partner to use a condom.

\section{STI Management Activities}

Providing sexually active men and women with services that can enable them to more effectively manage their risk of STI infection, treat existing infection and reduce transmission through sexual partners is an important component of integrated health services (MacNeil, 1996:98). There are number of activities that can be used by health services to detect and manage STIs more effectively.

Syndromic Management: One of the main tools of the integration model is the syndromic management approach recommended by the World Health Organisation. This approach does not try to diagnose specific STIs. Instead algorithms or flow charts are used to identify and treat specific syndromes such as vaginal discharge, urethral discharge in men, genital ulcers and pelvic pain. Syndromic management of STIs was the intervention that appeared to reduce the incidence of $\mathrm{HIV}$ infection in rural men and women by almost 40 percent in the community randomised study in the Mwanza Region of Tanzania (Grosskurth, Mosha and Todd, 1995:530). 
It became clear that most of the providers had heard about the syndromic management. However, some providers were not familiar with the principles underlying the syndromic management approach. In some of the health facilities the syndromic management approach is used but in most cases, STIs are rarely treated syndromically.

"I have heard about the syndromic management approach but I am not able to explain it. It is part of our policy but it is not implemented" (Rural, In-depth Interview).

Pelvic Examination: A pelvic examination is a critical procedure for STI diagnosis because it can be used to detect, through direct observation, signs that a woman may have but does not recognise (Askew, Magawa and Kangas, 1998:16). A pelvic examination also increases the likelihood of finding cases of reproductive tract infections (Askew, Magawa and Kangas, 1998:16). Many providers recognise the benefits of pelvic examination in allowing them to correctly diagnose and treat clients. However, in most cases, pelvic examinations of family planning clients do not routinely occur in many of the health facilities. They are usually only conducted on the basis of the client's complaints because providers assume that clients will not be willing to have a routine pelvic examination as part of their family planning consultation.

"Clients coming for family planning would not be willing to have a routine gynaecological examination. It is difficult for them to consent to a Pap smear, even after we explain to them the purpose. I don't think they will consent to an examination" (Rural, In-depth Interview).

Laboratory Testing: Laboratory testing facilities are usually not available in smaller health facilities. Laboratory facilities tend to be expensive and therefore are usually concentrated in the larger health facilities. Clients who are suspected of being infected with HIV are therefore usually referred to the larger health facilities for testing. Referral of blood samples to hospital laboratories for testing does not always function efficiently. Blood samples may not be collected promptly and therefore results are not returned promptly. Sometimes the results of the blood test may get lost during the transportation process, necessitating repeat tests.

"The whole process is very disorganised. Sometimes blood gets lost. This has a very negative effect on clients. They lose trust in providers. Sometimes the providers need to take blood for the second time. This creates an enormous amount of unhappiness among clients" (Urban, In-depth Interview).

Referrals may sometimes lead to delays in diagnosis and treatment. Clients also have to make two separate visits: one for the specimen to be taken and the other to obtain the results of the test. As a result, clients are not able to receive prompt treatment. In some cases, clients do not return for the test results.

Sometimes blood samples are taken from women without explaining the purpose of the test and this may lead to misunderstandings, as is illustrated in the following comment:

"Sometimes clients undergoing tests for syphilis may assume that they are tested for HIV/AIDS. As a result, if the results are positive, clients assume they are HIV positive. Clients are not given appropriate information and counselling about the purpose of the blood test" (Rural, Indepth Interview).

Risk Assessment: In the absence of pelvic and speculum examinations or laboratory facilities, risk assessment is the cornerstone of syndromic diagnosis as developed by WHO (Dehne, Snow and O'Reilly, 2000:631). Risk assessment, namely the identification through questions of risk behaviours, has been recommended as a useful tool to identify family planning clients with a high risk of infection and to improve the predictive value of the syndromic management approach (Askew, Maggwa and Kangas, 1998: 12). The risk assessment procedure may be used to substantiate clients' complaints, screen clients not aware of symptoms or determine further counselling needs (Fox, Williamson, Cates and Dallabetta, 1995:135). Opinions of providers were divided about the need for assessing the client's risk of STI. Some feel that risk assessment is difficult to implement because it requires asking clients several questions. Time constraints and heavy client loads make it difficult to screen all clients, as is illustrated in the following comment:

"There are about 300 or more clients that visit this health facility everyday. We are not able to provide clients with the services that we are supposed to provide them. The services we offer are largely determined by the size of the queue. We are always looking at the queue to see when we are likely to finish" (Rural, In-depth Interview).

Also, clients may resent being asked questions about their sexual behaviour. They may not see the relevance of the screening process. They would rather receive services for which they came to the health facility. Some providers feel that they are protecting the client's right to privacy by not screening them for STIs. However, some clients may be embarrassed to raise sexual health matters unless they are asked by the providers.

Some providers may not be comfortable discussing sexual matters with their clients, largely because their training did not prepare them for counselling on sensitive issues. Older providers may feel embarrassed to discuss sexual health matters with younger clients, as do female providers faced with male clients, as is illustrated in the following comment:

"Some may feel that the client is closer to their child's age and may feel embarrassed to discuss sexual matters with the client" (Rural, In-depth Interview).

Partner Notification: Partner notification is the process by which the partner of a person known to have a STI is informed that he or she has been exposed to a STI and encouraged to seek medical assistance (Macke, Hennessy, 
McFarlane and Bliss, 1998:561). Partner referral can be a highly effective strategy for ensuring that partners of patients infected with STIs receive prompt testing or treatment to avoid complications and eliminate asymptomatic infections (Macke, Hennessy, McFarlane and Bliss, 1998:561; Gorbach, Devgi, Celum, Stoner, Whittington, Galea, Coronado, Connor, Holmes, 2000:193). Partner notification has not been very successful because many of the clients often failed to bring their partners for treatment.

"Women don't want their partners to know that they have a STI. They are afraid of their partner's reaction. They are scared of their partner rejecting them. Most women are not working and they are financially dependent on their partners. Men have the final say in the household" (Rural, In-depth Interview).

Often women do not inform their partners that they have a STI because they are afraid that it may create conflict with their sexual partners.. Some providers mentioned that clients are afraid that it will raise some questions about their fidelity, as is illustrated by the following comment: "sometimes the woman may be shy to tell her partner that she has sores in her private parts because the partner would ask her where she got it from because he does not have it." Furthermore, some clients may have many sexual partners and, as a result, may not be able to identify the source of infection. This is illustrated in the following comment:

"You will find that a client has many sexual partners. Some men tell us that they don't know who they must bring to the clinic because they have so many sexual partners" (Urban, focus group discussion).

Some men and women may not be able to get into contact with all their partners because some may have been casual or anonymous. Also, sometimes women are not able to bring their partner for treatment because of the limited opening hours of the health facility.

\section{Conclusion and Recommendations}

Integrated reproductive health services have been proposed as a comprehensive approach to meeting the needs of clients. It became clear that integrated services are seen as a more client centred approach because it services the needs of clients more efficiently and effectively. Clients are offered a full range of services on a single visit. Integrated services are seen as benefiting clients because it reduces their travelling times and clients are saved the inconvenience of coming to the clinic on many separate occasions. In principle, most providers favour the integration of services. However, in terms of practical implementation, there is a lack of clarity about the precise form that integration should take. The process of integration at the district level is likely to progress more efficiently if providers were given clear guidelines for implementing integrated services.

Providers are accustomed to treating family planning and
STIs separately and may be reluctant to deal with broader sexual health matters. Helzner and Roitsein (1995:81) argue that most family planning workers focus only on the risk of unwanted pregnancy with the result that they "often abstracted sexual intercourse from sexuality, from the social and cultural context in which it occurs and from the wide range of sexual and reproductive health needs of clients". This is clearly illustrated by the study conducted in KwaZulu-Natal to determine provider's ability and preparedness to prevent the spread of HIV among teenagers (Abdool Karim, Preston-Whyte and Abdool Karim, 1992:361). They found that, despite their awareness of AIDS, service providers perceived their main role to be that of promoting contraception. Family planning staff rarely considered the possibility of prescribing condoms together with a more reliable contraceptive method because they perceive their role as primarily that of birth control. Condoms were perceived as an unreliable method of contraception and their use was discouraged. The present study found that condoms are more likely to be associated with disease- rather than pregnancy-prevention. As a result, family planning clients are more likely to receive information about more highly effective methods of preventing pregnancy that they may use without their partner's knowledge. Providers have an important to play in promoting condoms as a method of dual protection against the risk of unwanted pregnancy and STIs/HIV.

Clients visiting health facilities are rarely offered a comprehensive range of services that will protect them against the risk of unwanted pregnancy and STIs/HIV. Clinics may lack the personnel and resources needed to undertake STI management activities. Prevention activities are more easily incorporated into their activities than STI management activities, which is consistent with findings from other studies (Dehne Snow and O'Reilly, 2000:630). The client load, however, made it difficult for staff to provide screening for all their clients. As a result, providers usually offer STI services to clients that complain of symptoms or explicitly present with signs that suggested a STI. An expanded package of reproductive health services is likely to increase the responsibilities of service providers. Some of the providers have received specialist training and are not adequately prepared to provide a comprehensive range of services. Poor compliance with syndromic management protocol could also be due to the complicated nature of the algorithms (Shelton, 1999:149). The existence of sufficient numbers of adequately trained providers at all levels is essential for the successful implementation of integrated services. Perhaps, as suggested by Harrison, Wilkinson, Lurie, Connolly and Abdool Karim (1998:2334), training should occur in clinics, rather than centrally, to allow all clinic staff to participate.

One of the arguments in favour of integration is that quality, or effectiveness, of services would be improved through the delivery of integrated services. However, effective implementation is hindered by a host of logistical problems. Many of the common complaints are very similar to those mentioned in many different settings, and included insufficient space; high case loads, lack of adequate staff prepa- 
ration and training, shortage of equipment and infrastructure, as well as poor morale, low pay and high turnover (Magwaza and Cooper, 2002:38; Lush, Walt, Cleland and Mayhew, 2001:40). Another problem is the inefficient referral system, which means that clients do not receive services promptly.

Another rationale for integrating family planning and STI services was the trimming of costs involved in operating various services, which served broadly simlar functions, separately. It was envisaged that the existing infrastructure could be used to offer a broad range of services. However, the lack of adequate infrastructure could seriously impede the efficient delivery of services. Many providers reported that they were not able to undertake certain activities because of infrastructural constraints. In some cases, the physical structure of the health facility was not able to accommodate the increase in clients, which limited the service offered to clients. Providers reported not conducting verbal screening of clients because of the lack of privacy. In the short term, the feasibility of the integrated approach is dependent on the adequacy of the existing health infrastructure. More effort has to be expended on improving the infrastructure at health facilities.

\section{References}

ABDOOL KARIM,Q; PRESTON-WHYTE, E \& ABDOOL KARIM, SS 1992: Teenagers seeking condoms at family planning services. Part II: A Provider's Perspective. South African Medical Journal. 82: 360-362.

ASKEW, I; MAGGWA, N \& KANGAS, L 1998: Integrating STI and HIV/AIDS services into MCH/FP programmes in East and Southern Africa. Paper presented at the Annual Meeting of the Population Association of South Africa. Chicago: Illinois.

BONGAARTS, B AND JOHANNSON, E 2002: Future Trends in Contraceptive Prevalence and Method Mix in the Developing World. Studies in Family Planning. 33(1): 24-36.

DEHNE, K; R. SNOW, R \& O'RELLLY, KR 2000: Integration of Prevention and care of sexually transmitted infections with family planning services: what is the evidence for public health benefits? Bulletin of the World Health Organisation. 78: 628-639.

DEVELOPMENT BANK OF SOUTH AFRICA 1998: KwaZulu-Natal Development Profile. KwaZulu-Natal, Development Bank of South Africa. Development Information Business Unit. Development Paper 133.

FINGER, W 1994: Should Family Planning include STD services? Network. 14: 4-7.

FOX, L; WILLIAMSON, NE; CATES, W \& DALLABETTA, G 1995: Improving Reproductive Health: Integrating STD and Contraceptive Services. JAMWA. 50:
129-136.

GORBACH, PM; DEVGI, OA; CELUM, C; STONER, BP; WHITTINGTON, WLH; GALEA, J;CORONADO, N; CONNOR, S \& HOLMES, KK 2000: To Notify or Not to Notify: STD Patient's Perspectives of Partner Notification in Seattle. Sexually Transmitted Diseases. 27: 193-200.

GROSSKURTH, H; MOSHA, F \& TODD, J 1995: Impact of improved sexually transmitted diseases on HIV infection in rural Tanzania: randomized controlled trial. The Lancet. 346: $530-536$.

HARRISON, A; WILKINSON, D; LURIE, M; CONNOLLY, AM \& ABDOOL KARIM, S 1998: Improving quality of sexually transmitted disease case management in rural South Africa. AIDS. 12: 2329-2335.

HELZNER, J \& ROITSTEIN, LF 1995: HIV/STD Prevention in Family Planning Services: Training as a Strategy for Change. Reproductive Health Matters. 5: 80 - 88 .

KREFTING, L 1991: Rigor in qualitative research. The assessment of trustworthiness. The American Journal of OCcupational Nurses. 45 (3) 214-219.

LECLERC-MADLALA, S 1997: Infect One, Infect All: Zulu Youth Response to the AIDS epidemic in South Africa. Medical Anthropology. 17:363-380.

LUSH, L; CLELAND, J; WALT, G \& MAYHEW, S 1999: Integrating Reproductive Health: Myth and Ideology. Bulletin of the World Health Organisation. 77: 771-777.

LUSH,L; WALT, G; CLELAND, J \& MAYHEW, S 2001: The role of $\mathrm{MCH}$ and FP services in HIV/STD control: Is Integration the answer? African Journal of Reproductive Health. 5: 29-46.

MACKE, B; HENNESSY, M; MCFARLANE, MM \& BI ISS, MJ 1998: Partner Notification in the Real World: A Four Site Time Allocation Study. Sexually Transmitted Diseases. 25: $561-568$.

MACNEIL, J 1996: Integrating STD Services into Reproductive Health Services. In Control of Sexually Transmitted Diseases: A Handbook for the Design and Management of Programs. Dallabetta, G; Laga, M \& Lamptey, P. Arlington: AIDSCAP Project.

MAGWAZA, S \& COOPER, D 2002: Reproductive Health Service Integration in South Africa. Nursing Standard. 16: 33-39.

MAYHEW, S 1998: Health Care in context, policy into practice: a policy analysis of integrating STD/HIV and $\mathrm{MCH} / \mathrm{FP}$ services in Ghana. London. Unpublished PhD dissertation. London: University of London.

NEUMAN, WL 1994: Social research methods: qualitative and quantitative approaches. Boston: Allyn and Bacon. 
PACHAURI, S 1994: Relationship between AIDS and Family Planning Programmes: a rationale for developing integrated reproductive health services. Health Transition Review. 4 (Supplement): 321-347.

SHELTON, J 1999: Prevention First: A Three Pronged Strategy to Integrate Family Planning Program Efforts against HIV and Sexually Transmitted Infections. International Family Planning Perspectives. 25: 147-152.

SIMMONS, R \& ELIAS, C 1994: The Study of ClientProvider Interactions: A review of Methodological Issues. Studies in Family Planning. 25(1): 1-16.

STRAUSS, A \& CORBIN, J 1990: Basics of Oualitative Research. Newbury Park: Sage.

UNAIDS 2002: AIDS Epidemic Update-December 2002. Geneva: UNAIDS.

VARGA, C 1999: South African young people's sexual dynamics: implications for behavioural responses to HIV/ AIDS. In Resistance to Behavioural Change to Reduce HIV/ AIDS Infection edited by Caldwell, J; Caldwell, P \& Anarfi J. Canberra: Health Transition Centre.

ZABA, B; BOERMA, T \& MARCHANT, T 1997: Family Planning in the era of AIDS: A social science handbook. Paper presented at the International Union for the Scientific Study of Population Workshop. Kenya: Nairobi. 